\title{
Effects of Knowledge Management on the Operational Performance of the B\&B Industry
}

\author{
Jui-Lung Chen ${ }^{1}$ \\ ${ }^{1}$ Department of Business Administration, National Chin-Yi University of Technology, Taiwan, R.O.C. \\ Correspondence: Jui-Lung Chen, Department of Business Administration, National Chin-Yi University of \\ Technology, No.57, Sec. 2, Zhongshan Rd., Taiping Dist., Taichung 41170, Taiwan, R.O.C. Tel: \\ 886-4-2392-4505. E-mail: leonchen@ncut.edu.tw
}

Received: May 10, 2016 Accepted: June 4, 2016 Online Published: July 27, 2016

doi:10.5539/ijms.v8n4p67 URL: http://dx.doi.org/10.5539/ijms.v8n4p67

\begin{abstract}
The bed and breakfast $(\mathrm{B} \& \mathrm{~B})$ industry has become a hot tourist and leisure industry in recent years. As consumers pay attention to vacation, there has been increasing competition in the B\&B industry. The industry needs to change the traditional management ideas and achieve sustainability through strategic management. Buttressed by the information technology, knowledge management takes the generation, application and consumption of knowledge and information as main resources and features zero consumption, instant sharing and sustainability. With the constant renewal of the information technology and the rapid development of the Internet network, knowledge management has imposed tremendous challenge on the B\&B industry and played a key role in the operation of the industry. This study aims to explore the effects of knowledge management on operational performance in the B\&B industry. The research results can serve as strategic suggestions and reference for the practitioners of the industry in their operation and management.
\end{abstract}

Keywords: B\&B industry, knowledge management, operational performance

\section{Introduction}

In recent years, there has been a rise in the bed and breakfast $(\mathrm{B} \& \mathrm{~B})$ tourism. The fast-growing $\mathrm{B} \& \mathrm{~B}$ industry has also led to fierce competition in the domain. In comparison with other tourist accommodation industries, the $\mathrm{B} \& \mathrm{~B}$ industry integrates local industries with culture and natural and ecological resources and fascinates domestic and foreign tourists with the unique local humanistic charm. Especially for the modern people who face great pressure in work and life, taking part in tourist and leisure activities has become an effective way of relaxing themselves (Chen \& Yang, 2005). The advanced industrialized countries, in particular, entail sufficient leisure activities in their economic growth. Therefore, the increasing public demands for leisure has accelerated the advancement of the tourist industry; the preference for leisure tourism has gradually shifted to countryside experience where people can enjoy nature, pursue physical and mental cultivation, and acquire knowledge through entertainment according to local cultures (Huang, Hsiao, \& Li, 2009). In most cases, the rise in the B\&B industry in many countries is the result of the fact that there are an adequate number of restaurants or hotels in the tourist destinations during vacations. To solve the problem, the families who have empty houses near the tourist destinations offer the B\&B service. Originally, only the simple accommodation service was offered. With the social development and the competition in the industry, many countries have gradually introduced the catering and tourist guide services to the B\&B industry and attracted tourists with distinctive architectural appearance and special operation. Recently, some governments and private businesses have invested great passion in various tourist activities to promote economy and aroused a heated wave of leisure tourism as well as $\mathrm{B} \& \mathrm{~B}$ tourism. Moreover, the B\&B industry has become diversified, differentiated and theme-oriented. The ever stronger consumer awareness has gradually changed the demand for the B\&B service: aside from visible comfort and sanitation, consumers seek invisible ideological identify or presumably abstract happiness (Lee, 2008). Hence, in the fierce competition, the B\&B practitioners strive to create different and distinctive services to enhance competitiveness, which has become an essential issue in the industry (Liu \& Wu, 2014).

Knowledge management has been applied to the business circuit since the 1970s. It brings enterprises remarkable economic profits, and its effectiveness has been widely recognized. As an important tool that enhances the competitiveness and survival of organizations, it has become an essential research field in recent 
years, including in the B\&B industry (Siau, Tan, \& Sheng, 2010). Due to the rapid development of the information technology, the traditional business model has to consistently change to adapt to the ever-changing business environment to survive (Kanagasabapathy, Radhakrishnan, \& Balasubramanian, 2006). With the constant advancement of social economy, many industries have become increasingly dependent on knowledge and information. How to innovate the management thoughts and methods of enterprises has become an important direction for corporate management. Compared with the traditional economic pattern, knowledge economy is an information technology-based expanded economy which takes the generation, application and consumption of knowledge and information as main resources and features zero consumption, instant sharing, and sustainability. Moreover, knowledge economy emphasizes digging more implicit knowledge for corporate management. Besides, knowledge resources can be repeatedly consumed and copied, playing a measurable role in economic growth. The popular networks and the rising E-commerce and network marketing have had significant effects on the operation of the B\&B industry. Knowledge management is the process where knowledge is created, obtained and applied to improve learning and organizational performance (Scarborough, Swan, \& Preston, 1999). Knowledge management strategies regard valuable knowledge inside and outside organizations as the most important resources. A series of strategies and measures are taken to achieve effective management, strengthen the knowledge innovation of organizations, and form and maintain the core competitiveness of organizations (Yu \& He, 2015). Effective knowledge management can help organizations accumulate core knowledge, acquire information and create competitiveness (Kanagasabapathy et al., 2006).

If the knowledge management in the operation of the B\&B industry can be achieved in such aspects as the acquisition and creation of knowledge, the refinement of knowledge, and the storage and sharing of knowledge, then it is possible to effectively enrich and manage expertise to satisfy diverse customer demands and enhance competitiveness and operational performance. Apart from the interior parts of organizations, knowledge management needs to focus on the vast amount of information outside the organizations. An ideal knowledge management system should be characterized with widely applying exterior information and accurately seeking useful information to reinforce innovation and core competitiveness of organizations. Therefore, following new management trends, developing new management thoughts, and using convenient information tools to enhance management effectiveness will lead to success in the B\&B industry. In the era of knowledge economy, the tourist industry has taken knowledge as a critical asset of organizations. Aside from creating value for organization, knowledge management has become one of competitive tools for organizations to optimize management procedures and increase operation effectiveness (Bahra, 2001; Hallin \& Marnburg, 2008). According to Turkson \& Riley (2008), applying the knowledge accumulated in education, learning and experience to the leisure and tourist industries can be seen as one of knowledge management approaches. The knowledge of leisure and tourist industries involves customers, products/services, operation procedures, competitors, and relevant workers (Yang \& Wan, 2004). Most of the previous studies on knowledge management gave priority to such industries as information technology, education and manufacturing, paying little attention to the B\&B industry. Hence, this study adopts the literature analysis and collects relevant books and academic papers to explore the effects of knowledge management on the operational performance of the B\&B industry. The author hopes that the achievements of this study will help the practitioners improve knowledge management and create and manage knowledge according to their needs and situations so as to achieve direct or indirect operation accomplishments. In addition, some conclusions will be drawn according to the research results and specific and substantial suggestions on operation improvement, policy-making, and tourist popularization strategies will be provided for the B\&B industry, relevant governmental institutions, and academic studies.

\section{Literature Review}

\subsection{Knowledge Management}

In the era of knowledge economy, knowledge has gradually replaced natural resources, capital and labor to become a main resource of enterprises as well as the primary resource for innovation (Yu \& He, 2015). With the advancement of knowledge economy, as a resource, has gradually evolved into a catalyst that enhances organizational competitiveness and even the driving force that urges people to constantly make progress and face new challenges and opportunities. Additionally, knowledge is also one of the most precious resources of enterprises and helps organizations develop competitiveness (Alavi \& Leidner, 2001; Ulka Toroand Joshi, 2013). Holsapple \& Joshi (2002) pointed out that knowledge consisted of knowledge acquisition, knowledge selection, knowledge internalization, knowledge application, knowledge generation, and explicit knowledge. Stewart (1997) believed that knowledge was invisible, expandable and fluid and can be shared. Knowledge is the countermeasures in adaption, survival and competitiveness which enterprises adopt to explore and acquire knowledge assets and seek new market opportunities throughout their entire development when they are 
confronted with an ever-changing inconsistent environment (Yogesh, 2000). Arthur Andersen and APQC (1996) defined knowledge management as a strategy which enabled appropriate people to obtain appropriate knowledge at an appropriate time and could help the members share information, turn it into the action that enhances organization benefits, and use collective wisdom to strengthen the organization's innovation and response to changes. Gartner Group (2002) regarded knowledge management as creating, selecting, organizing, storing, retrieving, and using the information assets of enterprises through cooperation and integration; these information assets includes databases, documents and, most importantly, implicit professional skills and the experience of some employees. Hanley \& Dawson (2000) said that knowledge management was the combination of principles, procedures, frameworks and applied technologies of organizational design and operation; it enabled knowledge workers to reveal their creativity and capabilities and create value for the enterprise with amazing efficiency. According to Andrew, Arvind, \& Albert (2001), knowledge management could formalize experience, knowledge and professional skills to develop a new ability to attain better performance and the ability to reform and enhance customer value. Nonaka \& Takeuchi (1995) divided knowledge into explicit knowledge and implicit knowledge: explicit knowledge could be signified by text and number and could be spread and shared through specific information, scientific formulas, standardized procedures or universal principles; implicit knowledge was highly personalized and hard to be formalized, spread and shared, including subjective intuition and presentiment; the creation of knowledge was based on the interaction between implicit knowledge and explicit knowledge, and the application of knowledge must be derived from knowledge conversion. According to Snowden (2002), knowledge management was the confirmation, optimization and positive management of wisdom assets which included the explicit knowledge of artificial finished products or the implicit knowledge of individuals and communities; therefore, knowledge management could be divided into the management of explicit knowledge and the management of implicit knowledge. O'Dell, O'Dell, Grayson, \& Essaides (1998) regarded knowledge management as a "meaningful strategy which provides appropriate knowledge for appropriate people and helps them share knowledge and apply information to the action aimed for improving organizational performance." Coleman (1997) pointed out that knowledge management was a procedure through which people could obtain and share learning experience and use the experience to enrich personal knowledge and increase the value of organizations.

Knowledge management strategy can be divided into conservative knowledge management strategy and positive knowledge management strategy (Zack, 1999). Different knowledge strategies have different knowledge orientations, knowledge accumulation routes and knowledge capacities, which affects organizational innovation. According to Cohen \& Levinthal (1990), knowledge management strategy dominated an enterprise's knowledge management, determined its resource allocation, and promoted organizational reform and innovation. Davenport \& Prusak (1998) pointed out that knowledge management aimed to establish knowledge bases, improve the accesses to knowledge and knowledge environment, and manage knowledge as assets. Survey (1999) believed the so-called knowledge management was a business process as well as a procedure where a company created or used its knowledge; it comprised of three main procedures: (1) organizational learning: the company obtained information or knowledge; (2) knowledge production: the original information was converted into the knowledge that solved business problems; (3) knowledge distribution: the members of the organization were allowed to use the internal, shared knowledge of the company. From the perspective of organizational ability, Andrew et al. (2001) divided knowledge management into knowledge management infrastructure and knowledge management capability; knowledge management should involve the establishment of the work environments which supported employees, including organization culture, organization structure, the support and application of information technology, and knowledge strategy; these environments could be called as the basic construction of knowledge management. Andrew et al. (2001) adopted knowledge management ability to measure an organization's basic construction of knowledge management and took it as a comprehensive indicator of the efficiency of the knowledge management procedure. The basic construction of knowledge management can be divided into technology, structure and culture. The ability of knowledge management procedure involves such management procedures as the acquisition, conversion, application and protection of knowledge. Hence, enterprises need to manage invisible assets like knowledge property right and commercial reputation, create an environment for the accumulation, innovation and application of knowledge and, if possible, establish knowledge archives or knowledge bases. In this way, the originally scattered experience-based knowledge can be collected to help enterprises acquire managerial experience.

\subsection{Operational Performance}

In an environment featuring fierce competition, enterprises would not merely rely on scale economy, technology, patent and capital to achieve success; instead, they would depend more on the competitiveness based on 
innovation, speed and adaptability (Pfeffer, 1994; 1998). To maximize the effectiveness of organization knowledge and increased organizational wealth, organizational knowledge management aims to effectively manage the knowledge asset, knowledge facility, those with knowledge, and knowledge innovation, with emphasis on the acquisition, accumulation, sharing and innovation of knowledge. Lee \& Choi (2003) compared a company with others in success, market share, growth rate, profit-earning ability and innovation to measure organization performance. Kaplan \& Norton (1992) proposed the balance score card, with the hope of seeking a balance between short-term and long-term objectives, between financial and non-financial measurement, between lagging and leading indicators, and between external and internal performance dimensions; hence, he believed that such dimensions as finance, customer, internal performance as well as learning and growth should be used to measure an organization's overall performance. Meanwhile, these four dimensions were also the directions for enterprises to implement visions and strategies in operation; they listed all the problems to be considered in each dimension and the general measurement indicators that most enterprises would adopt. The knowledge sharing in an organization can effectively enhance the innovation and overall performance of the organization; knowledge sharing can not only strengthen the innovation and learning ability of enterprise employees but also enable the learning curve of enterprises to decline quickly, enable enterprises to swiftly reduce production marginal cost and meet customer demands, and form the invisible knowledge assets of enterprises (Andrews \& Delahaye, 2000; Nonaka \& Takeuchi, 1995; Kessel, Kratzer, \& Schultz, 2012). Andrew et al. (2001) found that knowledge management has measurable effects on organizational performance. According to the finding of Alavi \& Leidner (2001)'s study on knowledge management, knowledge is highly important for personal growth and enterprise competitiveness, but it is impossible to know what kind of knowledge ability and structure would affect organizational performance; therefore, knowledge management not only involves a passive search and acquisition of knowledge but also includes the sharing and transfer of knowledge and active learning. The knowledge sharing and the sharing of experience and knowledge of different fields in an organization can enhance the organization's abilities and then the overall competitiveness (Keams \& Lederer, 2003). Therefore, current enterprises rely on not only asset accumulation but also knowledge accumulation and renewal to develop themselves. Enterprises need to take knowledge management as their important strategic resources and coordinate information, market, management and operation skills, so as to improve operation in a more effective way. Only by applying knowledge management to all parts of management can enterprises give full play to knowledge, maximize the value of knowledge and attain greater economic development.

\section{Research and Analysis}

At present, the $\mathrm{B} \& \mathrm{~B}$ industry features diverse patterns, varieties and themes, and the operation themes include special views, special ecology, local food, cultural and historical features, and industrial production (Huang et al., 2009). Its range covers orchard, pasture, mountain and seafront. Its greatest features are diversity and exquisiteness. In particular, B\&B products stand out in the rural tourism industry. Most of B\&B services are in private operation rather than in chain operation, characterized with private services and certain degree of communication with owners (Morrison, 1996). Generally, there are two kinds of B\&B: one is accommodation-oriented $\mathrm{B} \& \mathrm{~B}$ which features a clean and refreshing environment and a cheap price near scenic spots; the other is specialty and service-oriented $B \& B$ which features a courtyard, the exquisite design of the owner, the food made by the owner, the lifestyle of the owner, and the typical warm atmosphere of home. The greatest difference between B\&B and restaurant is that the guesthouse owner, like a friend whom you haven't met for a long time, would help plan the whole trip and all activities from the moment the guesthouse is booked. Accommodation is an important factor tourists would take into account. Aside from the traditional standard restaurants, tourists can choose the special guesthouses that interest them, which will be a wonderful experience and choice. However, different demands for guesthouses would lead to different kinds of consumption (Lin, 2010). There are a variety of guesthouses, which offers more choices of accommodation for a trip to Taiwan but also attracts foreign tourists. To enhance their competitiveness, the B\&B practitioners have been strived to make their business more exquisite and special (Liu \& Wu, 2014).

What distinguishes a guesthouse from a hotel or a resort is that a guesthouse not only provides accommodation but also conveys a humanistic sense and a warm sense of home to tourists. Apart from an accommodation different from that in a traditional hotel, the B\&B tourists expect an interaction with the guesthouse owner (Warnick \& Klar Jr., 1991). The B\&B industry not only offers some communication with the guesthouse owner but also gives tourists opportunities to get acquainted with local environment or buildings or participate in special activities (Pearce \& Moscardo, 1992). According to Stutt \& Wortman (2005), the B\&B industry had five features - regional, unique, different, participatory, and interactive. Yen (2003) noticed in his study that most 
consumers were fascinated by landscape guesthouses, especially the clean ones with a theme and that they often traveled with their friends and family members. Tourist magazines are the main source of the information about guesthouses for consumers. Some studies have shown that tourists attach importance to the interaction with the owner of the guesthouse and the experience exchange with other tourists. Loker-Murphy \& Pearce (1995) pointed out that free tourists preferred to a low-price accommodation, the interaction with other tourists, an independent arrangement and a flexible itinerary, a vacation longer than a common one, and informal and participatory vacation activities (Ross, 1993). Additionally, what free tourists expect most is a pleasant experience of local folk customs. However, the extra functions of the B\&B industry have gradually become the main motives that attract consumers, replacing the low price which was taken as a consumers' attraction in the early stage, improving guesthouses, and creating broader prospect and development potential for the B\&B industry (Hsu \& Huang, 2004). In the accommodation industry, guesthouses provide basic accommodation facilities and services, help ease the problem of inadequate number of hotel guesthouses in the popular tourist destinations, and offer basic and small accommodation facilities and equipment in the remote areas which have a few hotels (Chuo \& Wang, 2014; Hung \& Li, 2015).

Lee \& Choi (2003) thought that knowledge management not only involves all kinds of information and knowledge but also a tool which helps increase efficiency and maintains information. According to the results of Andrew et al. (2001)'s study on American enterprises from the perspective of knowledge management "ability", there was a positive correlation between knowledge management and operational performance. Nevertheless, it is not long since knowledge management has been applied to the management of the B\&B industry as a new management model; we are still in the stage of exploring and trying it, without any available experience. In the B\&B management system, the knowledge management module is often confined to the management of customer information, the construction of websites and networks, and other visualized fields; it has not become common in the implementation and popularization of knowledge management. The integration, sharing and transmission of rich information resources enable employees and customers to achieve joint progress, help organizations realize operational objectives, and enhance organizational efficacy (Vander Merwe, 1999). Yang, Ma, \& Su (2011) found that innovative business procedures helped establish a positive correlation between the technological and cultural abilities and the market; there was relevance between the cultural ability and the market performance. Chen \& Cheng (2011) noticed that intra-enterprise knowledge transfer could enhance a person's customer service orientation and improve the overall performance of the organization. Lee \& Choi (2003) put forward an integration framework to illustrate that knowledge creation involved much basic construction of knowledge management which consisted of organization culture, organization structure, people, and the support and application of information technology; the basic construction of knowledge management could activate the knowledge creation in the organization; moreover, knowledge creation could also intensify organizational creativity and influence organizational performance. Yamin, Gunasekaran, \& Mavondo (1999) elaborated on the relationship between innovation indication and performance and found that there was a significant correlation between organizational innovation and managerial innovation, technological innovation and product innovation. Damanpour \& Evan (1984) studied organizational innovation and its effects on organizational performance and drew the conclusion that organizational innovation could be divided into technological innovation and managerial innovation and that the organizational performance based on technological innovation and managerial innovation was great. According to Lin (2010), most tourists obtained the information about guesthouses on the Internet; the B\&B practitioners could establish guesthouse websites and update them regularly to enhance tourists' intention of accommodation; in other marketing dimensions, they could join some $\mathrm{B} \& \mathrm{~B}$ associations or make a legal registration on the official website of the tourist bureau; moreover, the assistance of local governments and the establishment and connection of B\&B websites and blogs also captivated the attention of free tourists (Hsiao \& Chuang, 2014). Meanwhile, B\&B practitioners should acquaint themselves with the demand and expectation of tourists and take the demand and expectation as the variable of market segmentation in their selection of target markets and their making of marketing strategies. L's study made a consensus map of B\&B guests and proposed their image framework which consisted of five dimensions - mind, facility and landscape, growth and exchange, play, and visual expectation. Therefore, the $\mathrm{B} \& \mathrm{~B}$ practitioners need to develop the view that keeps pace with times and seize the opportunities of development in the market; besides, they should establish a rational talent incentive mechanism, a knowledge management mechanism and a strategic management mechanism as soon as possible, so as to fulfill operation objectives with modern management.

\section{Conclusions and Recommendations}

The popularization of networks has changed consumer behaviors, transformed operator management, and 
created various innovative online business models. Applying the knowledge management model to the B\&B industry is a groundbreaking attempt and is still in the stage of exploration. With focus on how to strengthen the practitioners' abilities to manage knowledge, apply knowledge management to the management of the B\&B industry and give full play to knowledge management to keep a balance between explicit knowledge and implicit knowledge and finally promote the operational performance of the industry, this study has drawn the following conclusions and give the following suggestions.

The $\mathrm{B} \& \mathrm{~B}$ industry is an emerging tourist and leisure industry in recent years. If the $\mathrm{B} \& \mathrm{~B}$ practitioners integrate local cultures, industrial features and natural and ecological resources and strive to create local charms in the operation, they will be able to attract more tourists with local features. To attain long-term development in the market, enterprises must acquire useful information in time; hence, it is imperative for enterprises to establish effective channels for information transmission. First, the B\&B practitioners must invest more capital to purchase the equipment necessary for the establishment of the information transmission channels, such as computer software and hardware. Second, rational management systems must be established to ensure the continuity of information transmission. Meanwhile, it is necessary to define the responsibility of relevant workers in some key parts to guarantee the effective information transmission. Only by achieving constant innovation with information technology and taking knowledge as the main production factor can enterprises increase the additional value of products and services and thus enhancing competitiveness. Specifically, the knowledge management system can help members share information and give full play to collective wisdom so as to enhance the organization's innovation and response to emergencies and improve its innovation performance. From the angle of knowledge creation, Eriksson \& Dickson (2000) divided knowledge sharing into cognition and behavior. While sharing and using knowledge, people are also creating new knowledge. The knowledge sharing in an organization can accelerate knowledge innovation and improve the organization's innovation and performance (Nonaka \& Takeuchi, 1995). As for how to increase the effectiveness of knowledge management in the $\mathrm{B} \& \mathrm{~B}$ industry, it is necessary to take the industry as a knowledge camp and disperse implicit and explicit knowledge in all directions and among all members. To establish a knowledge management system is to collect and summarize the scattered knowledge and present it as encoded explicit knowledge for the sharing and innovation of knowledge. In terms of the establishment of a knowledge management system, the first step is to construct a knowledge management mechanism and designate a commissioner to manage and sort out knowledge and make a systematic categorization so that he/she can help other members search and use the knowledge. Moreover, it is necessary to summarize the categorized knowledge on a regular basis and remove the knowledge which is inconsistent with the development of the practitioners or lacks value, so as to achieve constant renewal of knowledge. An incentive mechanism of knowledge sharing must be established to stimulate members' intention of knowledge sharing and innovation and gradually develop their inertia and initiative awareness of knowledge sharing and innovation; second, a technological support system of knowledge management must be built. The system, in fact, is an online platform where members can exchange and share knowledge and make a statistical analysis of the demand for knowledge so as to take it as a basis for the future collection of knowledge; lastly, the knowledge map technology should be applied to knowledge management, which will not only show members the quantity and storage of knowledge but also give them a convenient access to knowledge. Knowledge sharing can be seen as the communication and learning among employees and groups. In the learning, individual knowledge can be converted into organizational knowledge, and the primary task of the organization is to promote the continuous learning in the organization (Senge, 1997). Normally, the organization is saturated with information, but the information will not be counted as knowledge until it is applied; only the cognitive results obtained from the analysis and understanding of information can be regarded as real knowledge. Meanwhile, open-minded, agreeable and responsible employees have significant positive effects on knowledge sharing (Matzler, Renzl, \& Mitller, 2008). In the process of value creation, enterprises must consistently develop corporate meaning. Only by doing so can they give a full play to the positive role of knowledge and make more profits in economic management.

In many countries across the world, the $\mathrm{B} \& \mathrm{~B}$ industry is an essential leisure industry. The management of the industry must be combined with local industries, cultures, and natural and ecological resources to actively create regional charm and a high-quality rural resort with sustainable development. For instance, ecological tourism, in-depth tourism, regular destination tourism and knowledge-based tourism should developed to attract more tourists. The operation of the industry should meet the following requirements: have a large number and an appropriate range; maintain current landscape; reduce damage to nature, maintain or carry forward traditional features; strengthen the organizational function of communities; improve community environment; create features according to local natural resources; landscape and industries; embody knowledge in entertainment activities (Woodside \& Lysonski, 1989). Therefore, the B\&B practitioners must pay attention to the geographical 
location of guesthouses and the famous scenic spots in the surrounding areas, so as to shorten the round-trip time of tourists, make full use of shared brands of tourist destinations, and equip the architectural style, decoration and additional facility of guesthouses with such theme as humanity and ecology, so as to attract more tourists and enhance consumers' accommodation intention and satisfaction (Liu \& Wu, 2014). Moreover, the practitioners must recognize the importance of knowledge economy management and take it as the core competitiveness of enterprises in the future, so as to give full play to knowledge management and enhance management efficiency and level. To find out new development directions, enterprises must continuously strengthen their abilities and strive to enhance the overall qualities of their employees, so as to consistently create and realize value in the development. In the new era, the focus of the management of human resources has gradually shifted to the creativity and problem-solving ability of talents; therefore, the management of human resources in the industry needs to be reinforced, such as increasing the number of employees, preparing adequate talents for corporate development, paying attention to employee quality, intensify the development of human resources, and making the plans of human resource management, so as to increase the utilization of employees and spur corporate development. Also, enterprises need to take effective measures to build a positive corporate image to enhance brand competitiveness. The practitioners should carry out differentiated product strategies - strengthening technological innovation in a targeted way and actively developing creative products that meet customer needs, so as to fascinate more potential customers in the market. Moreover, some enterprises can adopt new technologies and devices according to their core products, improve and innovate existing products and service, and enhance the performance and additional value of products and services to satisfy the competitive needs in the market. In terms of brand operation, the practitioners should implement brand strategies in all aspects of operation, which will increase the competitiveness of the practitioners in the expansion of the operation market. To this end, the practitioners need to develop correct brand awareness, implement brand strategies, and create brand personality, so that they will be able to accomplish long-term development in the market economy system. Last but not least, the government should work with the practitioners to push forward the industry so that it will become stronger and more competitive in the international tourist market and accelerate the development of the domestic tourist industry.

\section{Acknowledgement}

This research is supported by the National Chin-Yi University of Technology, Taiwan, R.O.C. (under Project\#: NCUT 16-R-MB-004).

\section{References}

Alavi, M., \& Leidner, D. E. (2001). Knowledge management and knowledge management systems: Conceptual foundations and research issues. MIS Quarterly, 25(1), 107-136. http://dx.doi.org/10.2307/3250961

Anderson, A. \& APQC. (1996). The knowledge-management assessment tool, prototype version, released at the knowledge imperative symposium. Houston: Developed by Arthur Anderson and the American Productivity and Quality Center.

Andrew, H. G., Arvind, M., \& Albert, H. S. (2001). Knowledge management: An organizational capabilities perspective. Journal of Management Information Systems, 18(1), 185-214. http://dx.doi.org/10.1080/07421222.2001.11045669

Andrews, K. M., \& Delahaye, B. L. (2000). Influences on knowledge processes in organizational learning: the psychological filter. Journal of Management Studies, 37(6), 2322-2380. http://dx.doi.org/10.1111/1467-6486.00204

Bahra, N. (2001). Competitive knowledge management. Basingstoke: Palgrave.

Chen, C., \& Yang, Y. (2005). The B\&Bs of leisure agriculture. TPE: Wiseman Publishing Co., Ltd.

Chen, W. J., \& Cheng, H. Y. (2011). Factors affecting the knowledge sharing attitude of hotel service personnel. International Journal of Hospitality Management, 31(2), 468-476. http://dx.doi.org/10.1016/j.ijhm.2011.07.005

Chuo, H., \& Wang, M. (2014). An analysis of destination competitiveness of Taiwan, Hong Kong and Macau from the perspective of tourism politics. Review of Global Politics, 45, 113-117.

Cohen, W. M., \& Levinthal, D. A. (1990). Absorptive capacity: A new perspectivem on learning and innovation. Administrative Science Qarterly, 35(1), 128-152. http://dx.doi.org/10.2307/2393553

Coleman, J. S. (1998). Social capital in the creation of human capital. American Journal of Sociology, 94, 95-120. 
Damanpour, F., \& Evan, W. M. (1984). Organizational innovation and performance: the problem of organizational lag. Administrative Science Quarterly, 29(3), 392-410. http://dx.doi.org/10.2307/2393031

Davenport, T. H., \& Prusak, L. (1998). Working knowledge: How organizations manage what they know. MA: Harvard Business School Press.

Eriksson, I. V., \& Dickson, G. W. (2000). Knowledge sharing in high technology companies. Proceedings of Americas Conference on Information Systems (AMCIS), 1330-1335.

Gartner Group. (2002). Management update: The 2002 knowledge management hype cycle. Inside Gartner This Week, 58(4), 23-31.

Hallin, C. A., \& Marnburg, E. (2008). Knowledge management in the hospitality industry: A review of empirical research. Tourism Management, 29(2), 366-381. http://dx.doi.org/10.1016/j.tourman.2007.02.019

Hanley, S., \& Dawson, C. (2000). A formwork for delivering value with knowledge management. The AMS knowledge centers. Information Strategy, 16, 27-36.

Holsapple, C. W., \& Joshi, K. D. (2002). Knowledge management: A threefold framework. The Information Society: An International Journal, 18(1), 47-64. http://dx.doi.org/10.1080/01972240252818225

Hsiao, T., \& Chuang, C. (2014). A Study on Supply and Demand of B\&B Reception for F.I.T from Mainland China to Taiwan. Web Journal of Chinese Management Review, 17(2), 1-24.

Hsu, Y., \& Huang, S. (2004). Market segmentation analysis of B\&B tourist. Journal of Hospitality and Home Economics, 1(1), 67-86. http://dx.doi.org/ 10.6572/JHHE.1(1).4

Huang, L., Hsiao, W., \& Li, J. (2009). Understanding tourism trends in the Lan Yang Area homestay trade: The Yosemite Bed and Breakfast as an example. The Journal of Liberal Arts and Management, 6, 209-233. http://dx.doi.org/10.6177/lam.2009.06.17

Hung, Y., \& Li, C. (2015). Discussion of the role and position of B\&B in the accommodation industry. Journal of Leisure, Tourism, Sport, \& Health, 5(2), 17-30.

Kanagasabapathy, K. A., Radhakrishnan, R., \& Balasubramanian, S. (2006). Empirical investigation of critical success factor and knowledge management structure for successful implementation of knowledge management system: A case study in process industry. Retrieved from http://knowledgemanagement.ittoolbox.com

Kaplan, R. S., \& Norton, D. P. (1992). The balance scorecard. MA: Harvard Business School Press.

Kearns, G. S., \& Lederer, A. L. (2000). The effect of strategic alignment on the use of is-based resources for competitive advantage. Journal of Strategic Information Systems, 9(4), 265-293. http://dx.doi.org/10.1016/S0963-8687(00)00049-4

Kessel, M., Kratzer, J., \& Schultz, C. (2012). Psychological safety, knowledge sharing, and creative performance in healthcare teams. Creativity and Innovation Management, 21(2), 147-157. http://dx.doi.org/10.1111/j.1467-8691.2012.00635.x

Lee, H., \& Choi, B. (2003). Knowledge management enablers, processes and organizational performance: An integrative view and empirical examination. Journal of Management Information Systems, 20(1), 179-228. http://dx.doi.org/10.1080/07421222.2003.11045756

Lee, I. (2008). The development and marketing strategies of the green B\&B of Japan. Journal of General Education Tainan University of Technology, 7, 356-379.

Lin, Y. (2010). A study of home-stay demand differences among various home-stay consumption segments. Journal of Sport and Recreation Research, 4(3), 85-105.

Liu, M., \& Wu, P. (2014). Establishing customer expected images of Bed and Breakfasts. Journal of Tourism and Leisure Studies, 20(2), 205-240. http://dx.doi.org/10.6267/JTLS.2014.20(2)4

Loker-Murphy, L., \& Pearce P. L. (1995). Young budget travelers: Backpackers in Australia. Annals of Tourism Research, 22(4), 819-843. http://dx.doi.org/10.1016/0160-7383(95)00026-0

Matzler, K., Renzl, B., \& Mitller, J. (2008). Personality traits and knowledge sharing. Journal of Economic Psychology, 29, 301-313. http://dx.doi.org/2007 10.1016/j.joep.2007.06.004

Morrison, E. W. (1996). Longitudinal study of the effects of information seeking on newcomer socialization. Journal of Applied Psychology, 78(2), 173-183. http://dx.doi.org/10.1037/0021-9010.78.2.173 
Nonaka, I., \& Takeuchi, H. (1995). The knowledge-creating company. NY: Oxford University Press.

O'Dell, C. S., O'Dell, C., Grayson, C. J., \& Essaides, N. (1998). If only we knew what we know: The transfer of internal knowledge and best practice. NY: Free Press.

Pearce, P. L., \& Moscardo, G. M. (1992). The boutique/specialist accommodation sector: Perceived government needs and policy initiatives. Australia: James Cook University.

Pfeffer, J. (1994). Competitive advantage through people. Boston: Harvard Business School Press.

Pfeffer, J. (1998). The human equation: Building profits by putting people first. Boston: Harvard Business School Press.

Ross, G. F. (1993). Destination evaluation and vacation preferences. Annals of Tourism Research, 20(3), 477-489. http://dx.doi.org/10.1016/0160-7383(93)90004-M

Scarborough, H., Swan, J., \& Preston, J. (1999). Knowledge management: A literature review (issues in people management). UK: Institute of Personnel and Development.

Senge, P. (1997). Sharing knowledge. Executive Excellence, 15(6), 11-12.

Siau, K., Tan, X., \& Sheng, H. (2010). Important characteristics of software development team members: An empirical investigation using repertory grid. Information Systems Journal, 20(6), 563-580. http://dx.doi.org/10.1111/j.1365-2575.2007.00254.x

Snowden, D. (2002). Complex acts of knowing: Paradox and descriptive self awareness. Journal of Knowledge Management, 6(2), 100-111. http://dx.doi.org/10.1002/bult.284

Stewart, T. A. (1997). Intellectual capital: The new wealth of organizations. Bantam: Doubleday Dell Publishing Group Inc.

Stutt, A. T., \& Wortman, J. F. (2005). Hotel and lodging management: An introduction. NY: John Wiley \& Sons.

Survary, M. (1999). Knowledge management and competition in the consulting industry. California Management Review, 41(2), 95-107. http://dx.doi.org/10.2307/41165988

Turkson, E. R., \& Riley, M. (2008). The problem of eliciting management knowledge: A case of research into hospitality management knowledge. International Journal of Hospitality Management, 27(4), 584-593. http://dx.doi.org/10.1016/j.ijhm.2007.08.007

Vander Merwe, S. (1999). Customer capitalism. London: Nicholas Brealey Publishing Ltd.

Warnick, R. B., \& Klar Jr., L. R. (1991). The bed and breakfast and small inn industry of the common wealth of Massachusetts: An exploratory survey. Journal of Travel Research, 29(3), 17-25. http://dx.doi.org/10.1177/004728759102900303

Woodside, A. G., \& Lysonski, S. (1989). A general model of traveler destination choice. Journal of Travel Research, 27(4), 8-14. http://dx.doi.org/10.1177/004728758902700402

Yamin, S., Gunasekaran, A., \& Mavondo, F. T. (1999). Innovation index and its implications on organizational performance: A study of Australian manufacturing companies. International Journal of Technology Management, 17(5), 495-503. http://dx.doi.org/10.1504/IJTM.1999.002733

Yang, C., Ma, C., \& Su, Y. (2011). Evidence-based investigation for determining the characteristics of knowledge management on organizational innovation within Taiwanese teaching hospitals. I-Business, 3(1), 30-34. http://dx.doi.org/10.4236/ib.2011.31005

Yang, J., \& Wan, C. (2004). Advancing organizational effectiveness and knowledge management implementation. Tourism Management, 25(5), 593-601. http://dx.doi.org/ 10.1016/j.tourman.2003.08.002

Yen, J. (2003). The study on pension's consumption behavior. TPE: Fu Jen Catholic University.

Yogesh, M. (2000). Knowledge management and new organization forms: A framework for business model innovation. Information Resources Management Journal, (1), 5-14. http://dx.doi.org/10.4018/irmj.2000010101

Yu, C., \& He, D. (2015). Knowledge Management Strategy, Knowledge Integration Mechanism and Radical Innovation Research. Science and Technology Management Research, 12(1), 181-185. http://dx.doi.org/10.3969/j.issn.1000-7695.2015.21.034

Zack, M. H. (1999). Developing a knowledge strategy. California Management Review, 41(3), 125-145. 


\section{Copyrights}

Copyright for this article is retained by the author, with first publication rights granted to the journal.

This is an open-access article distributed under the terms and conditions of the Creative Commons Attribution license (http://creativecommons.org/licenses/by/4.0/). 